Supplement of Atmos. Chem. Phys. Discuss., 15, 14027-14073, 2015

http://www.atmos-chem-phys-discuss.net/15/14027/2015/

doi:10.5194/acpd-15-14027-2015-supplement

(C) Author(s) 2015. CC Attribution 3.0 License.

(c) (i)

Supplement of

\title{
Can a coupled meteorology-chemistry model reproduce the historical trend in aerosol direct radiative effects over the Northern Hemisphere?
}

\section{J. Xing et al.}

Correspondence to: J. Xing (xing.jia@epa.gov, xingjia@tsinghua.org.cn)

The copyright of individual parts of the supplement might differ from the CC-BY 3.0 licence. 
The deseasonalized time-series of both observation-derived and simulated SWR and AOD in 8 regions are presented in Figure S1. Since the TOA SWR calculation in the model is simply from land surface albedo which is supposed to be stable, as well as the aerosol extinction, it's higher related to the AOD than the surface SWR which is calculated from more factors (e.g., aerosol direct and diffuse radiation effect near the surface). It is expected that more significant correlations would exist between simulated TOA SWR and AOD $(\mathrm{R}>0.9$ for most regions except in SHR where $\mathrm{R}=0.77$ ) than between simulated surface SWR and AOD. An exception occurs in SHR such that the simulated surface SWR $(\mathrm{R}=0.96)$ has a much better correlation with AOD than TOA SWR. This is because in areas with high surface reflectivity (low surface albedo) like SHR, there is a negative feedback from the aerosol absorption on TOA-DRE (Kim et al., 2005). Such feedback may reduce the correlation between TOA SWR with AOD. For observationderived data, the TOA SWR is observed directly by instruments. On the contrary, the satelliteretrieved AOD is used to estimate the surface SWR by CERES (Kato et al., 2013), and results in a better correlation with AOD compared to TOA SWR in all land regions and ocean region, NIN, with higher AOD levels.

\section{Reference:}

Kim, D., Sohn, B. J., Nakajima, T., and Takemura, T.: Aerosol radiative forcing over east Asia determined from ground-based solar radiation measurements, J. Geophys. Res., 110, D10S22, doi:10.1029/2004JD004678, 2005.

Kato, Seiji, Norman G. Loeb, Fred G. Rose, David R. Doelling, David A. Rutan, Thomas E. Caldwell, Lisan Yu, Robert A. Weller: Surface Irradiances Consistent with CERES-Derived Top-of-Atmosphere Shortwave and Longwave Irradiances. J. Climate, 26, 2719-2740. 2013, doi: http://dx.doi.org/10.1175/JCLI-D-12-00436.1 
(a) $\mathrm{ECH}$

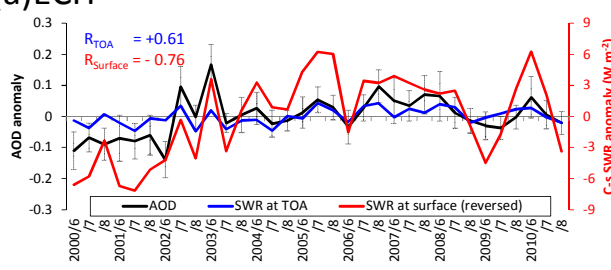

(b)EUS

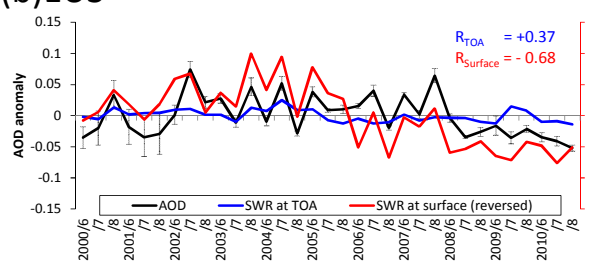

(c)EUR

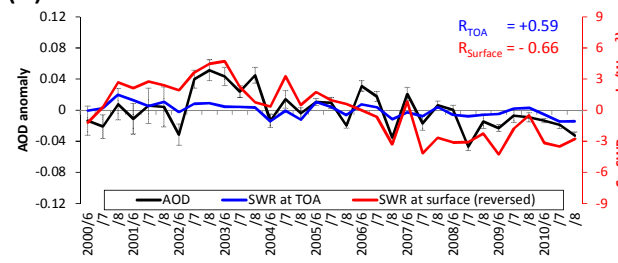

(d)SHR

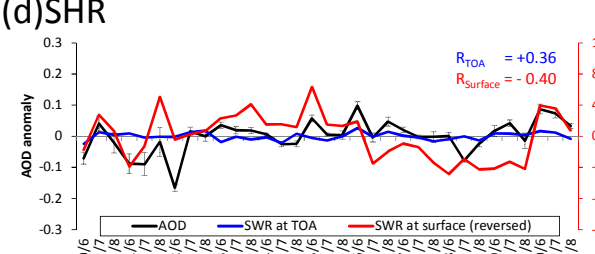

Sim.

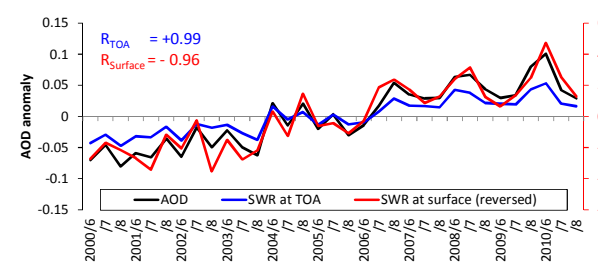

Obs.
Ocean regions

(e)NPA

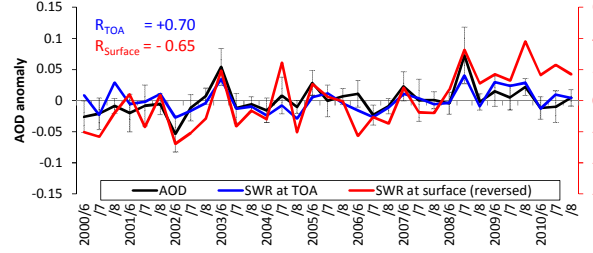

(f) NAT
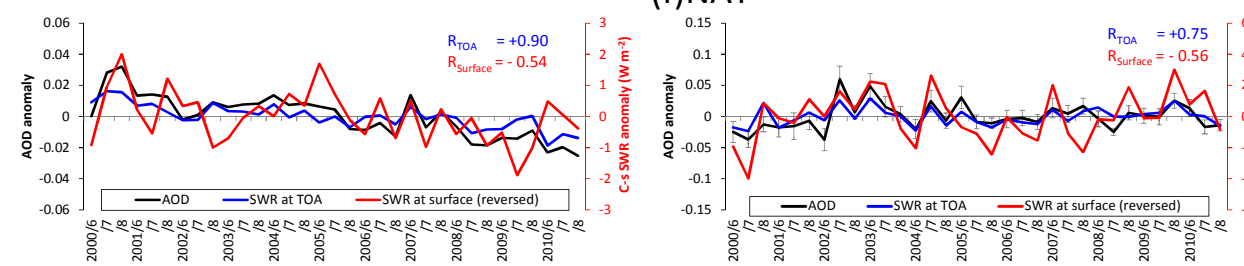

(g)CAT

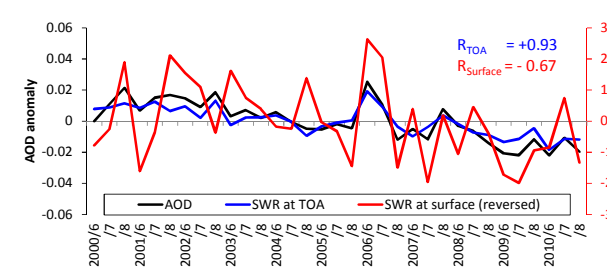

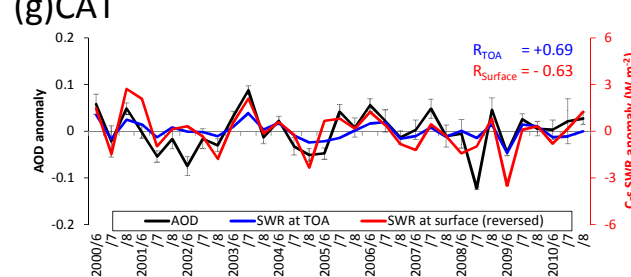
(h)NIN
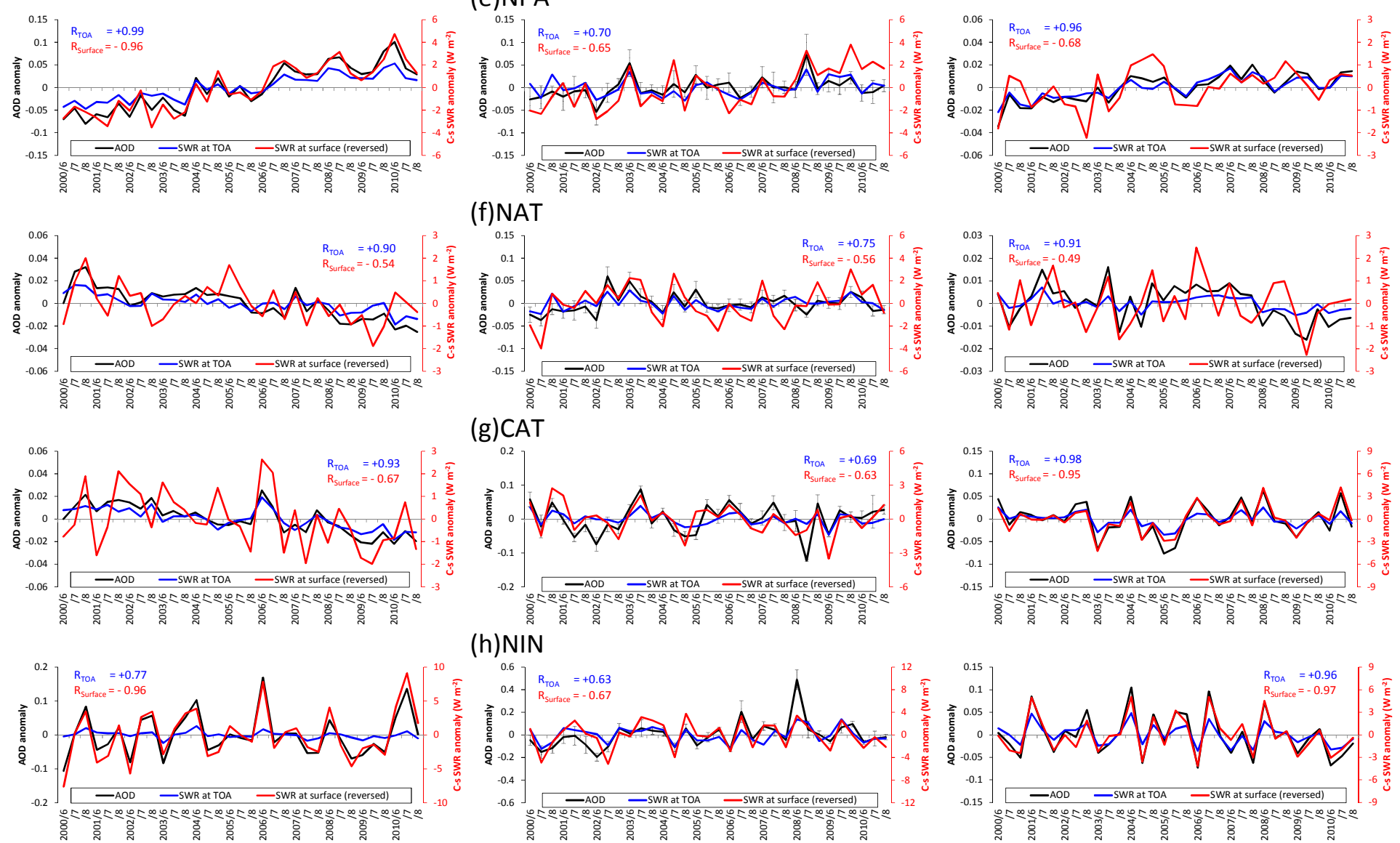

Fig. S1 Observed and simulated deseasonalized time-series of summertime SWR and AOD from 2000-2010 (regional monthly average, observed SWR is from CERES, observed AOD is the weighted average of 4 EOS satellites retrieves by available number of grids for calculation, see Fig. 3; their standard deviations $(0.5 \sigma)$ are shown as error bars) 
